\title{
Neutrophil depletion reduces edema formation and tissue loss following traumatic brain injury in mice
}

\author{
Ellinor Kenne ${ }^{1}$, Anna Erlandsson ${ }^{2}$, Lennart Lindbom¹ ${ }^{1}$ Lars Hillered $^{2}$ and Fredrik Clausen ${ }^{2 *}$
}

\begin{abstract}
Background: Brain edema as a result of secondary injury following traumatic brain injury (TBI) is a major clinical concern. Neutrophils are known to cause increased vascular permeability leading to edema formation in peripheral tissue, but their role in the pathology following TBI remains unclear.

Methods: In this study we used controlled cortical impact (CCl) as a model for TBI and investigated the role of neutrophils in the response to injury. The outcome of mice that were depleted of neutrophils using an anti-Gr-1 antibody was compared to that in mice with intact neutrophil count. The effect of neutrophil depletion on bloodbrain barrier function was assessed by Evan's blue dye extravasation, and analysis of brain water content was used as a measurement of brain edema formation (24 and 48 hours after CCI). Lesion volume was measured 7 and 14 days after CCI. Immunohistochemistry was used to assess cell death, using a marker for cleaved caspase-3 at 24 hours after injury, and microglial/macrophage activation 7 days after CCI. Data were analyzed using Mann-Whitney test for non-parametric data.

Results: Neutrophil depletion did not significantly affect Evan's blue extravasation at any time-point after CCl. However, neutrophil-depleted mice exhibited a decreased water content both at 24 and 48 hours after $\mathrm{CCl}$ indicating reduced edema formation. Furthermore, brain tissue loss was attenuated in neutropenic mice at 7 and 14 days after injury. Additionally, these mice had a significantly reduced number of activated microglia/ macrophages 7 days after CCl, and of cleaved caspase-3 positive cells $24 \mathrm{~h}$ after injury.
\end{abstract}

Conclusion: Our results suggest that neutrophils are involved in the edema formation, but not the extravasation of large proteins, as well as contributing to cell death and tissue loss following TBI in mice.

Keywords: Neutrophil, traumatic brain injury, brain edema, controlled cortical impact, neuroprotection, bloodbrain-barrier, cell death, microglia, neutrophil-depletion, mouse.

\section{Background}

The pathological response following traumatic brain injury (TBI) consists of the primary and secondary injury. The primary injury results in death of neurons and glial cells and widespread axonal damage at the moment of impact or acceleration/deceleration. This primary injury initiates a complex secondary injury cascade that includes intracranial inflammation and edema formation. Due to the non-expandable skull compartment, brain edema

\footnotetext{
* Correspondence: fredrik.clausen@neuro.uu.se

${ }^{2}$ Department of Neuroscience, Neurosurgery, Uppsala University, Uppsala, Sweden

Full list of author information is available at the end of the article
}

leads to increased intracranial pressure which in turn causes reduced perfusion and oxygenation of the tissue [1]. After a few days or weeks, the secondary injury cascade has left TBI patients with a much larger brain lesion and contributed to mortality among patients who survived the initial trauma [2].

Recruitment of polymorphonuclear leukocytes (PMN), specifically neutrophil granulocytes, is characteristic of the early inflammatory response following human TBI [3]. Neutrophil recruitment has been shown to increase over the first 24 hours after experimental TBI [4-6], and is dependent on both leukocyte CD11/CD18 [7] and endothelial intercellular adhesion molecule-1 (ICAM-1)
C Biomed Central 
[8]. It is well documented that neutrophils trigger alterations in vascular permeability leading to plasma leakage and edema formation in acute inflammation in peripheral tissue $[9,10]$. More specifically, this relies on neutrophil adhesion to the endothelial lining via $\beta_{2}$-integrins since functional blockade of the integrin adhesion molecule CD11/CD18 abolishes not only recruitment but also PMN-dependent plasma leakage [11]. The involvement of neutrophils in brain edema formation following TBI remains obscure and evidence exists both to support $[5,12]$, and refute their contribution to blood-brain barrier $(\mathrm{BBB})$ disruption $[4,13,14]$.

When neutrophils are recruited to a site of injury or infection they release a plethora of mediators such as reactive oxygen species (ROS), proteases and pro-inflammatory cytokines, all of which have the potential to adversely affect the integrity of the BBB [15]. The release of elastase and matrix metalloproteases from neutrophils has been shown to increase edema formation in animal models of stroke $[16,17]$. In accordance, depletion of neutrophils was found to result in an attenuated leakage of proteins across BBB following stroke [18]. Furthermore, cerebral PMN accumulation was correlated with increased intracranial pressure and brain water content after cryogenic brain injury [19].

Although several studies have suggested an important role for neutrophils in edema formation in the central nervous system (CNS) following stroke [20], the present study aims at clarifying the disputed role of neutrophils following TBI. Using the controlled cortical impact (CCI) model, which results in an ipsilateral cortical contusion and cavitation as well as scattered neuronal loss in the underlying hippocampus [21,22], we investigated edema formation in mice with normal levels of neutrophils and in mice that were depleted of neutrophils. In addition, the effects of induced neutropenia on brain tissue loss, apoptosis and microglia/macrophage activation after TBI were evaluated.

\section{Methods}

\section{Animals and treatment}

Male C57Bl/6 mice (Scanbur, Stockholm, Sweden) were kept at $24^{\circ} \mathrm{C}$, with $12 \mathrm{~h}$ light-dark cycles, and food and water ad libitum. Experiments were approved by the regional ethical committee for animal experimentation (reference number: C66/9) and followed the rules and regulations of the Swedish Agricultural Board. Neutrophil depletion (PMN depl) was achieved by i.p. injection of anti-Gr1 mAb RB6-8C5 (100 $\mu$ g, BioXCell, West Lebanon, USA) 12 hours prior to injury and again 12 hours after [23]. The antibody was administered i.p. to obtain a sustained depletion over the first 48 hours of the experiment. Differential white blood cell count using Türk staining in a Bürker chamber was performed at the time of injury to confirm that the PMN depletion was successful. The experiments were set up according to Table 1 . The animals experienced a small weight loss the day after TBI, but started to gain weight day 3 after injury and had recovered to original weight at day 7 . There was no significant difference between the treatment groups.

\section{Controlled Cortical Impact (CCI)}

$\mathrm{CCI}$ is one of the most widely used and characterized models of TBI in rodents $[21,24]$. Anesthesia was induced with inhalation of $4 \%$ isoflurane in air. During surgery, general anesthesia was maintained with a mix of isoflurane $(1.4 \%)$ and $\mathrm{N}_{2} \mathrm{O} / \mathrm{O}_{2}(70 / 30 \%)$, delivered through a nose cone. Mice were placed in a stereotaxic frame and core temperature was maintained at $37^{\circ} \mathrm{C}$ using a heating pad controlled by a rectal thermometer. Local anesthesia (Marcain, AstraZeneca, Sweden) was applied to the scalp and the skull was exposed by an incision along the midline. A craniotomy ( $4 \mathrm{~mm}$ diameter) was made over the right parietal cortex between the sutures of bregma and lambda using a dental drill. The cortical contusion was delivered by a $2.5 \mathrm{~mm}$ diameter piston set to an impact depth of $0.5 \mathrm{~mm}$ from a pneumatically driven CCI device (VCU Biomedical Engineering Facility, Richmond, VA, USA). The velocity of the piston was set to $2.8 \mathrm{~m} / \mathrm{s}$. The bone fragment was put back in place, secured with tissue adhesive (Histoacryl, Braun, Germany), and the scalp sutured. Naive mice did not undergo any surgical intervention or anesthesia. Animals were sacrificed at indicated time points (Table 1) with an overdose of pentobarbital (300 mg/kg, Apoteket, Sweden).

\section{Brain water content}

Immediately following sacrifice with pentobarbital, the brain was divided along the midline and the contralateral and ipsilateral tissue was weighed immediately following removal to obtain wet weight (WW). The tissue was then dried at $60^{\circ} \mathrm{C}$ for 72 hours and weighed to obtain dry weight (DW). Water content was calculated as a percentage of wet weight; $\%$ water content $=(\mathrm{WW}$ $\mathrm{DW}) / \mathrm{WW} \times 100$.

\section{Evans blue dye extravasation}

Mice were injected with $100 \mu$ l Evans blue (EB, 2\% in PBS, Sigma) through the tail vein at indicated times (Table 1). Evans blue dye injected intravenously binds instantaneously to albumin and other plasma proteins and serves as a marker for plasma exudation. Animals were sacrificed as described above and perfused with heparinized saline. Brain tissue from the contra- and ipsilateral side was analyzed. The tissue samples were snap frozen in $-55^{\circ} \mathrm{C}$ isopentane and freeze-dried. Freeze-dried specimens were homogenized in formamide $(1: 20 \mathrm{w} / \mathrm{v})$ and incubated at $60^{\circ} \mathrm{C}$ overnight. The 
Table 1 Experimental set up.

\begin{tabular}{|c|c|c|c|c|c|}
\hline \multicolumn{4}{|c|}{ Sample size } & \multirow[t]{2}{*}{ Time of sacrifice } & \multirow[t]{2}{*}{ Analysis } \\
\hline Naïve & Naïve + PMN depletion & $\mathrm{CCl}$ & $\mathrm{CCl}+\mathrm{PMN}$ depletion & & \\
\hline & & 8 & 5 & 24 hours & Evan's blue extraction (EB injection given 4 hours after $\mathrm{CCI}$ ) \\
\hline & & 7 & 7 & 24 hours & $\begin{array}{l}\text { Cleaved caspase-3 } \\
\text { Neutrophil accumulation }\end{array}$ \\
\hline 6 & 6 & 8 & 8 & 24 hours & Brain water content \\
\hline \multirow[t]{4}{*}{2} & 3 & 5 & 6 & 48 hours & Evan's blue extraction (EB injection given 24 hours after $C C I$ ) \\
\hline & & 9 & 9 & 48 hours & Brain water content \\
\hline & & 5 & 5 & 7 days & $\begin{array}{c}\text { Microglial/macrophage activation } \\
\text { Brain tissue loss }\end{array}$ \\
\hline & & 5 & 5 & 14 days & Brain tissue loss \\
\hline
\end{tabular}

homogenate was centrifuged at $14000 \mathrm{rpm}$ for $30 \mathrm{~min}$ and the EB content in the supernatant was determined spectrophotometrically at $620 \mathrm{~nm}$ (Titertek Multiscan).

\section{Lesion and Hemispheric Volumes}

Mice that were sacrificed one $(n=5+5)$ or two $(n=5$ $+5)$ weeks after injury were transcardially perfused with heparinized isotonic saline $(1000 \mathrm{U} / \mathrm{l})$ and then with phosphate-buffered $4 \%$ formaldehyde (Histolab AB, Gothenburg, Sweden). Following rapid removal the brain was placed in $4 \%$ formaldehyde in PBS at $4^{\circ} \mathrm{C}$ for 24 hours and $30 \% \mathrm{w} / \mathrm{v}$ sucrose at $4^{\circ} \mathrm{C}$ for 72 hours. It was then snap frozen in $-55^{\circ} \mathrm{C}$ isopentane. Seven sections from bregma levels -1 to $-4 \mathrm{~mm}, 500 \mu \mathrm{m}$ apart, were stained with Mayer's Hematoxylin and Eosin (Histolab) and, using a digital camera (mcm5c; Zeiss Gmbh), photographed in a stereomicroscope (Zeiss Stemi 2000$\mathrm{C}$; Zeiss Gmbh). The hemispherical volume and cortical lesion volume were calculated using ImageJ (NIH, Bethesda, MD, USA.). Volumes $(n)$ were calculated using the formula: $\Sigma_{\mathrm{n}=1}{ }^{7}\left(A_{n}+A_{n+1}\right) \times d / 2$, where $A$ is the hemispherical or cortical lesion area and $d$ the distance between sections [25]. Tissue loss of the ipsilateral (injured) hemisphere was calculated as a percentage of the contralateral (uninjured) hemispheric volume.

\section{Immunohistochemistry}

Immunohistochemistry was used to determine parenchymal cell apoptosis (cleaved caspase- $3, \mathrm{n}=7+7$ ) and neutrophil infiltration $(\mathrm{Gr}-1, \mathrm{n}=7+7) 24$ hours after CCI, and microglial/macrophage activation (Mac-2 expression, $\mathrm{n}=5+5) 7$ days after CCI. Brains were fixed as described above and cryosectioned to $12 \mu \mathrm{m}$ thick coronal sections, thawed and fixed in acetone for $1 \mathrm{~min}$. Normal horse serum (10\%) in PBS with $0.1 \%$ Triton-X-100 was used to block unspecific binding. Four sections, from different bregma levels were incubated with antibodies to cleaved caspase-3 (Cell Signaling Technology), Gr-1 (Abcam, Cambridge, U.K.) or Mac-2 (Cedarlane Laboratories, Burlington, ON, Canada) in PBS with $0.3 \%$ Triton X-100
(1:200) overnight. Following washing with PBS for $3 \times 5$ min, sections were incubated with an AlexaFluor-conjugated rabbit-anti-rat secondary antibody (Molecular Probes, Eugene, OR, USA, 1:200) in PBS with 0.1\% Triton-X-100 for $30 \mathrm{~min}$. Slides were washed with PBS and mounted using Vectashield with DAPI (Vector laboratories, Burlingame, CA, USA) as a nuclear marker. A fluorescence microscope system (Zeiss Axiovision, Zeiss Gmbh, Göttingen, Germany) was used to capture immunohistochemical images of cleaved caspase-3, Gr-1 and Mac- 2 staining at $100 \times$ magnification. Images from bregma levels $-1.5,-2.0,-2.5$ and $-3.0 \mathrm{~mm}$ were evaluated using Axiovision image analysis software. Three regions of interest $(600 \mu \mathrm{m} \times 800 \mu \mathrm{m})$ in the cortex and one in the dentate gyrus of the hippocampus were evaluated bilaterally in each animal (Figure 1).

\section{Statistics}

Statistical evaluations were made using Statistica (StatSoft, Tulsa, OK, USA). After testing the data for normality, the non-parametric Mann-Whitney test was used. Results are presented as means \pm SEM.

\section{Results}

\section{Controlled cortical impact causes PMN accumulation in cortical tissue}

Controlled cortical impact (CCI) was used as a model for TBI to investigate the role of neutrophils in the injury response. To confirm that the injury resulted in recruitment of PMN, brain sections taken 24 hours after injury were stained with an antibody against the Gr-1 antigen. In line with previous research [3-6], TBI resulted in accumulation of PMN in the injured cortex $(174.7 \pm 10.7$ cells/ field, Figure 2). As expected, this response was significantly reduced $(\mathrm{p}<0.05)$ in the neutropenic animals $(25.5 \pm 4.7$ cells/ field). In contrast to what was observed in the cortex, there was no obvious neutrophil recruitment to the hippocampus $(1.2 \pm 0.47$ cells/ field and $2 \pm 0.82$ cells/ field for neutropenic mice and control animals, respectively). In the contralateral cortex only a few $\mathrm{Gr}-1$ positive 


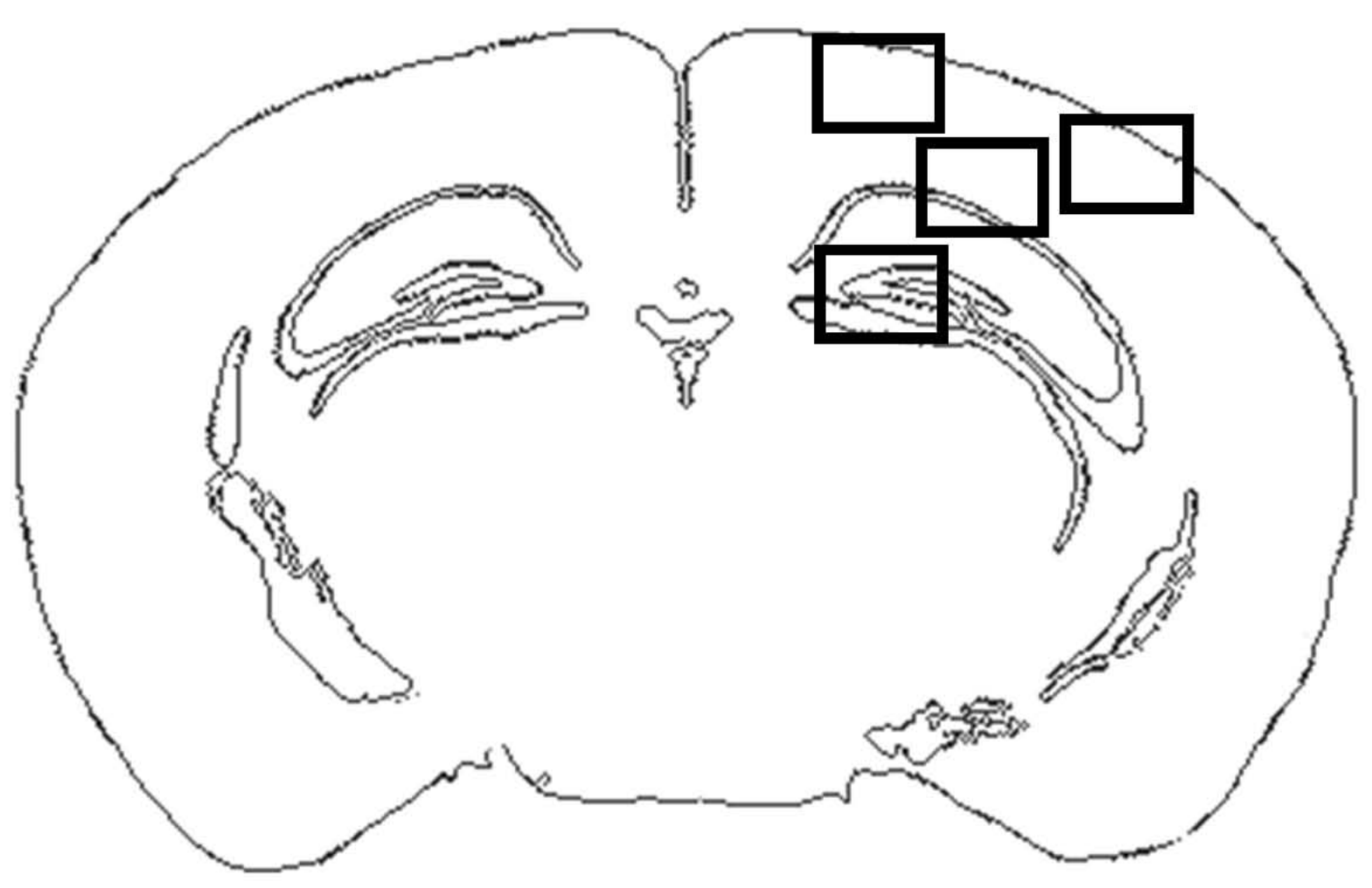

Figure 1 Three regions $(600 \times 800 \mu \mathrm{m})$ in the cortex and one in the dentate gyrus of the hippocampus were selected for counting of apoptotic cells and activated microglia/macrophages. The arrow indicates the presence of the contusion.

cells were found $(2.3 \pm 0.09$ cells/ field for neutropenic mice and $3.2 \pm 0.24$ cells/ field for control animals).

\section{Brain edema following TBI is neutrophil-dependent}

We used two methods to determine edema formation 24 and 48 hours following TBI. These time points were chosen as brain edema following CCI peaks during the first two days [26]. In addition, PMN accumulation following $\mathrm{CCI}$ is known to take place 24 and 48 hours after injury $[6,22,27]$. First, water content in the injured brain was used as a measure of edema after CCI. As expected, water content was significantly higher $(\mathrm{p}<0.05)$ in the ipsilateral side of the brain in mice that received TBI compared to naive animals (Figure 3A). Neutrophil depletion resulted in significantly decreased $(\mathrm{p}<0.05)$ water content in the ipsilateral hemisphere compared to untreated TBI animals both at $24 \mathrm{~h}(78.2 \% \pm 0.21 \%$ vs. $79.1 \% \pm 0.22 \%)$ and $48 \mathrm{~h}(78.8 \% \pm 0.21 \%$ vs. $79.9 \% \pm$ $0.53 \%)$ after injury. No statistical difference was observed in the contralateral hemisphere.

To further examine the effects of neutrophil depletion on plasma exudation we used Evan's blue dye as a marker for albumin extravasation (Figure 3C). Baseline leakage of EB was determined in naive mice and there was no difference between neutropenic and intact mice $(0.0325$ $\mathrm{AU} \pm 0.0013 \mathrm{AU}$ vs. $0.0308 \mathrm{AU} \pm 0.0030 \mathrm{AU}) \mathrm{CCI}$ resulted in a significant $(\mathrm{p}<0.05)$ increased EB extravasation in the injured area compared to the contralateral side or to naive animals at either time point after injury (Figure 3B). However, depletion of PMN did not result in attenuated levels of extracted EB compared to control mice at 24 hours $(0.1706 \mathrm{AU} \pm 0.0269 \mathrm{AU}$ vs. $0.1875 \mathrm{AU} \pm 0.0107$ $\mathrm{AU})$, or 48 hours $(0.0325 \mathrm{AU} \pm 0.0013 \mathrm{AU}$ vs. 0.0308 $\mathrm{AU} \pm 0.0003 \mathrm{AU})$. Taken together, these data indicate that PMN depletion counteracts the increase in brain water content, but does not protect from BBB breakdown following CCI.

\section{Neutrophil depletion attenuates tissue loss following TBI}

To determine the impact of PMN depletion during CCI on injury size later in the disease process, we analyzed lesion volume (Figure 4 A and $4 \mathrm{~B}$ ) and tissue loss, in the injured hemisphere in comparison to the uninjured hemisphere (Figure 4 C and 4D. Induced neutropenia resulted in significantly reduced $(\mathrm{p}<0.05)$ lesion volume two weeks after injury $\left(3.626 \pm 0.22 \mathrm{~mm}^{3}\right.$ for control and $2.488 \pm 0.23 \mathrm{~mm}^{3}$ for PMN depleted mice). There was a tendency for an attenuated lesion volume also at 


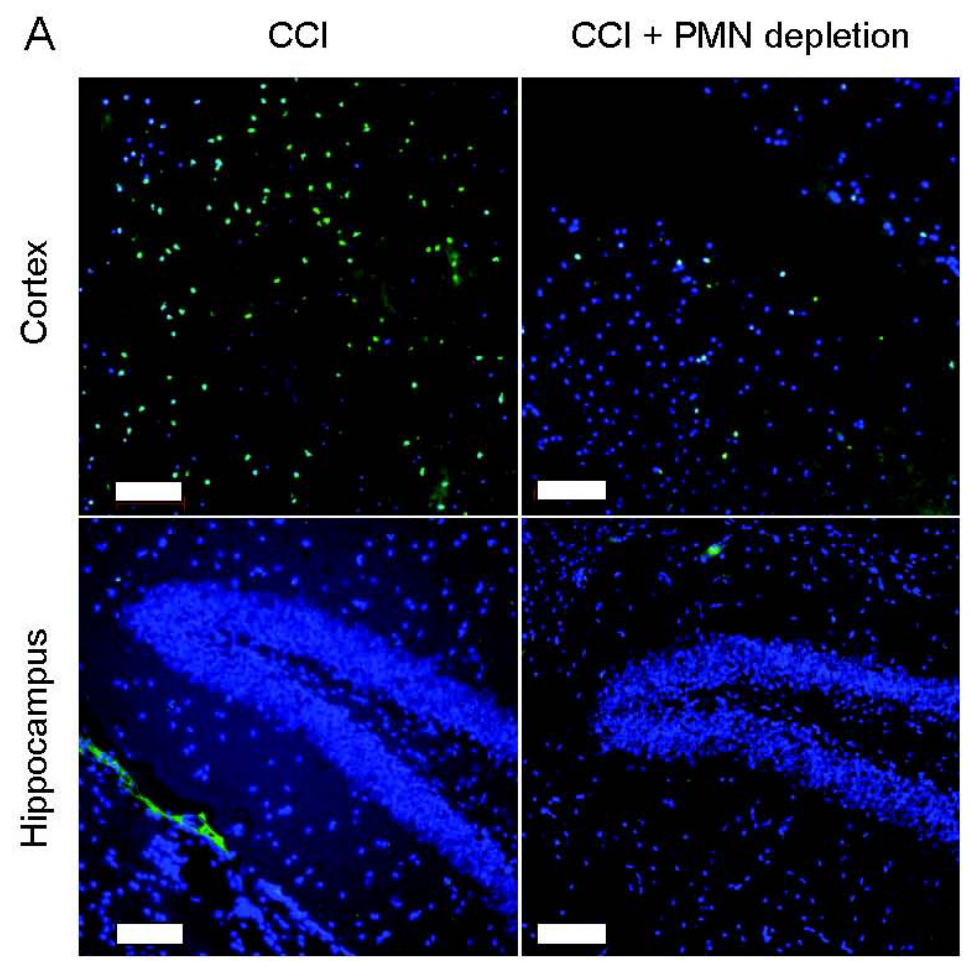

B
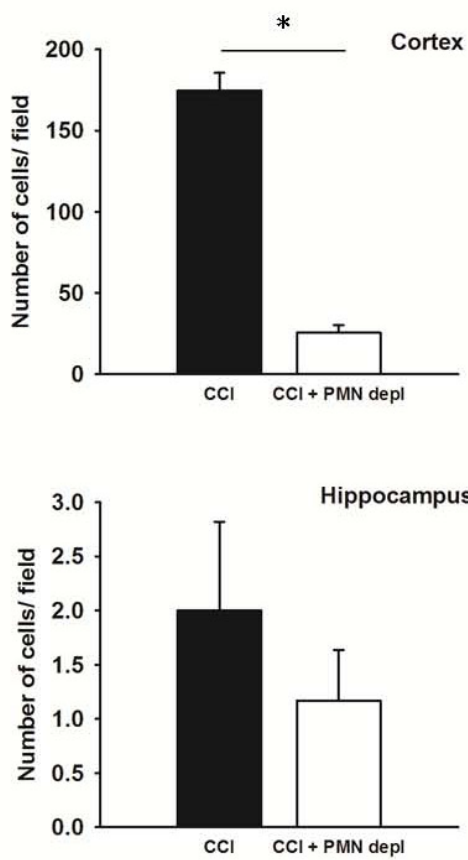

Figure 2 Neutrophil accumulation in the injured cortex 24 hours after injury is dramatically reduced in neutropenic mice. A) Micrographs of $\mathrm{Gr}-1$ positive cells (green) 24 hours after $\mathrm{CCl}$ in the cortex and hippocampus. Blue represents nuclear staining using DAPI. Scalebar is $100 \mu \mathrm{m}$. B) Quantification of Gr-1 positive cells in the cortex and hippocampus of intact (black bars, $\mathrm{n}=7$ ) and PMN-depleted (open bars, $n=7$ ) mice. * indicates significant difference at $p<0.05$. Values are mean $\pm S E M$.

one week after injury in the PMN depleted mice, although the difference was not significant $(3.646 \pm 0.58$ $\mathrm{mm}^{3}$ for control and $2.208 \pm 0.08 \mathrm{~mm}^{3}$ for PMN depleted mice) Furthermore, in neutrophil-depleted mice there was a significant reduction $(\mathrm{p}<0.05)$ of ipsilateral hemispheric tissue loss compared to injured control mice both at seven $(5.9 \pm 0.85 \%$ vs. $10.3 \pm 1.61 \%)$ and fourteen $(10.9 \pm 1.1 \%$ vs. $17.2 \pm 1.7 \%)$ days after injury (Figure $4 \mathrm{~A}$ and $4 \mathrm{~B}$ ). These data strongly suggests that neutrophil depletion at the time of injury protects from brain tissue damage.

\section{Neutrophil depletion reduces apoptosis $24 \mathrm{~h}$ after injury}

Apoptotic cells, as determined by cleaved caspase- 3 staining, were assessed in the cortex and the dentate gyrus of the hippocampus 24 hours after TBI (Figure 5). As expected, the hemisphere ipsilateral to the injury showed an increased number of apoptotic cells, both in cortex and hippocampus, compared to the contralateral side. Neutropenia significantly reduced $(\mathrm{p}<0.05)$ the number of cleaved caspase- 3 positive cells in the cortex $(187.3 \pm 37.4$ cells/ field vs. $293.2 \pm 28$ cells/ field), but not in the dentate gyrus $(41.1 \pm 9.5$ cells/ field vs. $50.2 \pm$ 9.7 cells/ field), indicating that the accumulation of PMN in the cortex contributes to caspase- 3 activation.

\section{Microglial/macrophage activation is attenuated in neutrophil-depleted mice}

In order to investigate the effect of neutropenia on microglial/macrophage activation, immunostaining with specific antibodies to Mac-2 was performed on brain sections from animals 7 days post injury, based on previous time course studies [22]. The hilus of the dentate gyrus was chosen to evaluate the injury to the hippocampus, as in our hands this area shows the most change after CCI. Mac-2 positive cells in the ipsilateral hippocampus and cortex were assessed using a fluorescence microscope (Figure 6A). There was a large number of activated microglia/macrophages in the cortex after TBI, which was significantly $(\mathrm{p}<0.05)$ reduced in the PMN-depleted group (99.7 \pm 14 cells/ field vs. $144.8 \pm 15$ cells/ field; Figure 6B). On the other hand, counting the number of positive cells revealed that there was only a small number of activated microglia/macrophages in the dentate gyrus of the 

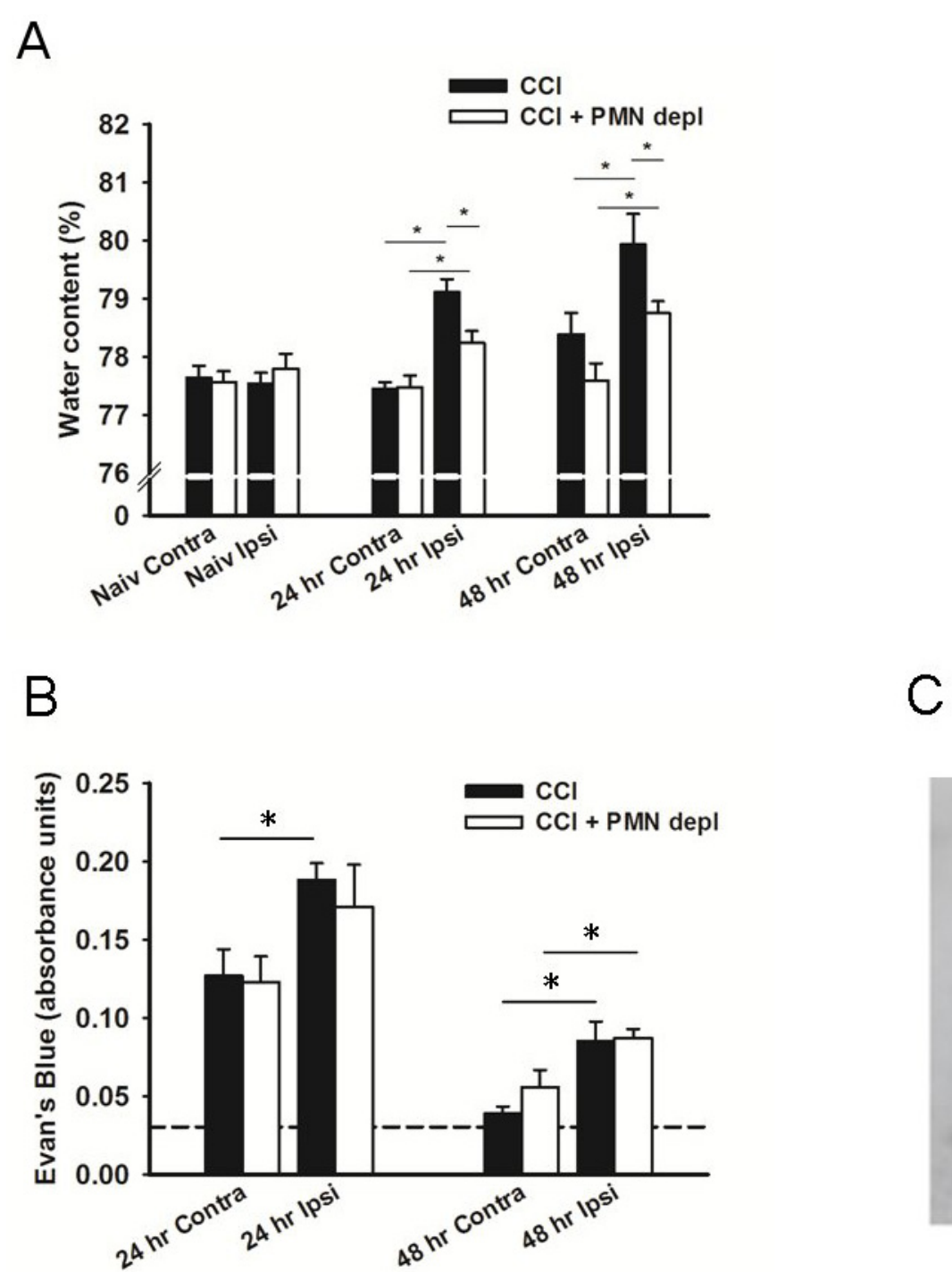

Figure 3 Brain water content but not macromolecule extravasation following TBI is affected by neutrophil depletion. A) Brain water content in the contralateral and ipsilateral areas 24 and 48 hours after $C C l$ in intact (black bars, 24 hrs: $n=8,48$ hrs: $n=9$ ) and PMN-depleted (open bars, 24 hrs: $\mathrm{n}=8,48$ hrs: $\mathrm{n}=9$ ) mice. Values for naïve mice are provided for comparison. B) Evan's blue content in the contralateral and ipsilateral sides 24 and 48 hours after $C C l$ in intact (black bars, 24 hrs: $n=8,48$ hrs: $n=5$ ) and PMN-depleted (open bars, 24 hrs: $n=5,48$ hrs: $\mathrm{n}=6$ ) mice. Dashed line represents baseline EB leakage in naïve mice 24 hours after injury for comparison. ${ }^{*}$ indicates significant difference at $p$ $<0.05$. Values are mean \pm SEM. C) Representative image of EB leakage 24 hours following CCI.

hippocampus (Figure 6B), $10.3 \pm 3.2$ cells/ field for neutropenic mice and $10.5 \pm 2.2$ cells/ field for control animals. These data are in line with a previous study of neutrophil depletion in a model of intracerebral hemorrhage (ICH) [18].

\section{Discussion}

Cerebral edema and secondary injury are feared complications of TBI. Recruitment of neutrophil granulocytes is known to cause increased vascular permeability and edema formation in peripheral tissue. However, the connection in the CNS between neutrophil emigration and edema formation is not clear. Therefore, this study used antibody-induced neutrophil depletion to investigate the role of neutrophils in brain edema formation following $\mathrm{CCI}$ in mice. As additional endpoint parameters, we looked at the brain tissue loss, microglia/macrophage activation and apoptosis of cells in the injured area.

Cerebral edema is a consequence of structural and functional changes of the BBB, the microcirculation or of parenchymal cell volume regulation, and can be classified as cytotoxic or vasogenic. Cytotoxic edema occurs as a result of intracellular swelling of glia and neurons and may arise independently of the integrity of the BBB, as a 


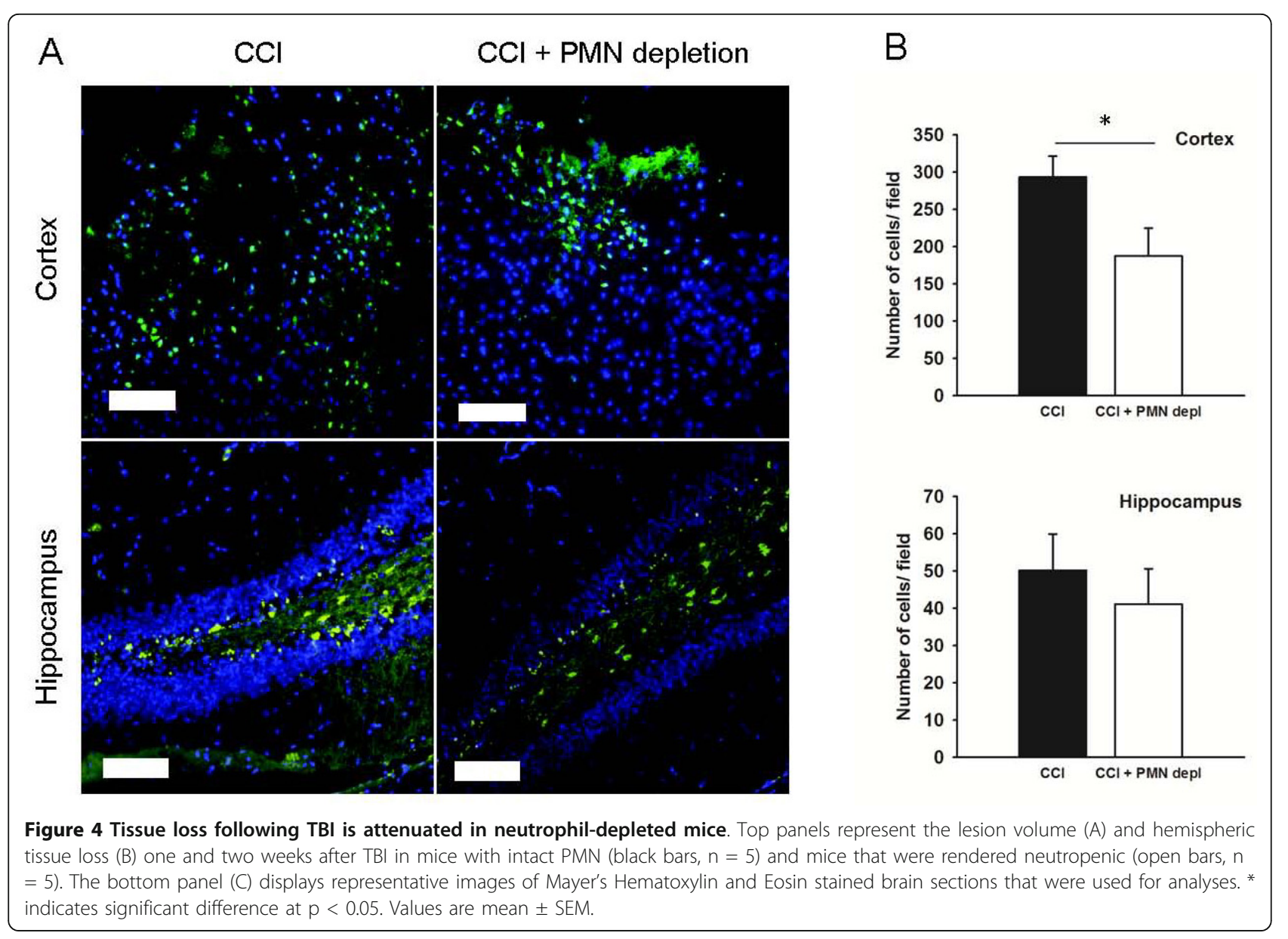

result of energy metabolic crisis and perturbation of ion homeostasis. A disruption of the BBB or disturbances in the microcirculation on the other hand results in vasogenic edema [1]. Increased brain water content is an important clinical feature of TBI potentially resulting in raised intracranial pressure, lowered cerebral perfusion pressure and eventually reduced cerebral blood flow with impaired glucose and oxygen delivery to the brain tissue [1]. Brain water content has been shown to increase following TBI in rodents and remain elevated for up to 7 days [28]. As PMN do not seem to mediate the early BBB breakdown, during the first 4 hours, after trauma [29], we investigated the effects of PMN depletion on cerebral edema formation 24 and 48 hours after injury. By measuring brain water content we show that the edema after CCI is attenuated in mice that are depleted of neutrophils. This attenuation was maintained for at least 48 hours after injury. In order to assess whether disruption of the BBB and plasma extravasation (vasogenic edema) contributed to the increased brain water content during the first days after injury, we used Evan's blue as a marker for macromolecule extravasation. However, our results suggest that the enhanced macromolecular leakage across the BBB 24 or $48 \mathrm{~h}$ after injury occurred independently of neutrophils. It is known that neutrophil-adhesion to postcapillary venules in peripheral tissue results in decreased endothelial barrier function and extravasation of macromolecules [10]. Our results indicate that the BBB might respond differently to neutrophil adhesion. This difference could be explained by the morphology, biochemistry and function of the BBB that are distinct from that of the endothelial lining in peripheral tissue [30]. Another possibility is that the mechanical trauma from the CCI results in a breakdown of the BBB that is independent of PMN recruitment. Thus, the strong mechanical impact on the blood vessels and the hemorrhage formed will mask any PMN-dependent leakage that is evident in response to a more diffuse injury $[5,12,31]$. Moreover, cerebral edema and macromolecular leakage have been shown not to be temporally correlated [1] indicating that $\mathrm{BBB}$ breakdown is not the only factor leading to edema following TBI. For example, osmotic brain edema caused by imbalances between blood and brain tissue, e.g. hyponatremia, is a common feature of clinical TBI [1]. It is therefore possible that the edema formation may increase without EB leakage being 


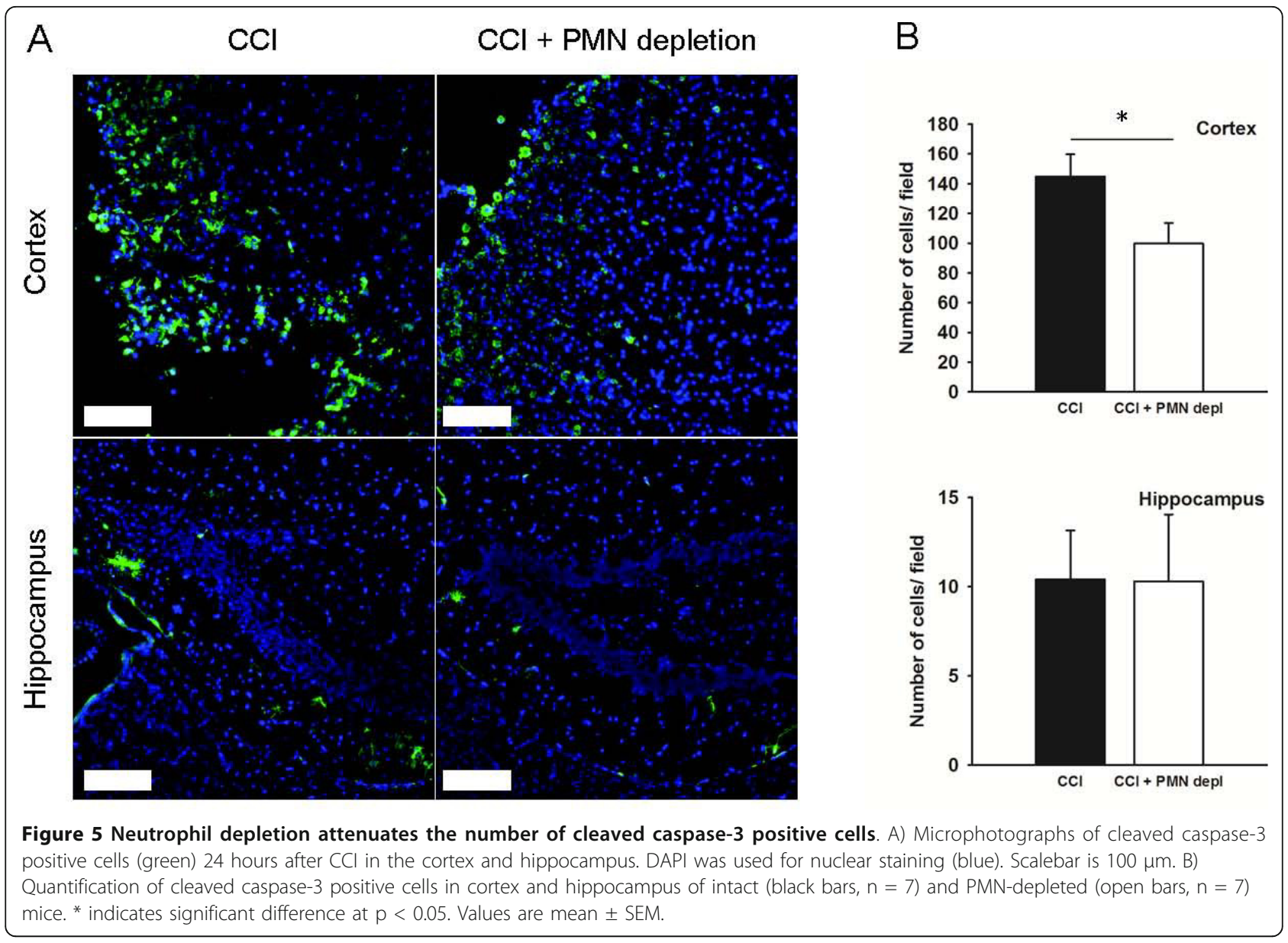

affected [32], perhaps explaining the results of the present study.

Possible mechanisms behind the neutrophil-dependent tissue swelling in our study could be release of ROS and proteases such as matrix metalloproteinases (MMPs) in the parenchymal tissue leading to breakdown of cells and a cytotoxic edema. Modulation of free radicals seems to improve several parameters, such as edema formation, injury size and neurological score, after TBI [33]. PMN derived substances such as MMPs and ROS, have been shown to have a direct cytotoxic effect on neuronal cells in vitro [34], which could explain the increasing brain water content seen after injury. The cytotoxic effects of PMN may explain the attenuation in apoptotic cell count in neutropenic animals. However, it is difficult to discern whether the apoptotic cells cause the edema or vice versa.

Acute injury to the brain activates the microglia and the release of pro-inflammatory cytokines [35]. It has been shown that neutrophils may stimulate recruitment and activation of monocytes/macrophages in peripheral tissue [36]. Here, we show that microglial/macrophage activation is less prominent in mice that are rendered neutropenic, which suggests a similar relationship between neutrophil recruitment and phagocytic cell activation in the brain as in peripheral tissue. This relationship is further strengthened by the lack of PMN accumulation in hippocampus, which is associated with few apoptotic cells and activated microglia/macrophages. Our findings are supported by previous research using a model of intracerebral hemorrhage in rat, where neutropenia resulted in significantly reduced number of activated microglia/ macrophages 7 and 14 days after injury [18]. The results described in this study might also be due to an attenuation of the secondary injury caused by PMN thus requiring less activation of microglia/ macrophages.

In addition to decreased apoptosis, we show that neutrophil depletion results in attenuated brain tissue loss and lesion volume following TBI. The neuroprotective effect of neutropenia was significant at both 7 and 14 days after injury. Thus, there is a beneficial effect of early PMN depletion in the injury development, possibly due to less PMN-related cytotoxicity, less edema or a reduced number of inflammatory cells in the injured area. Several studies have shown an association between 
A

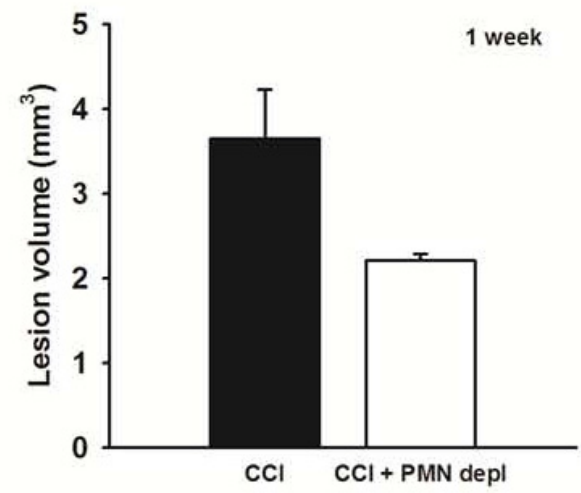

B

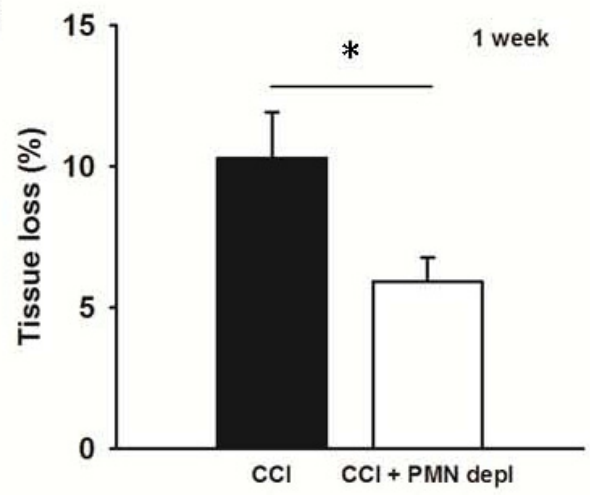

C

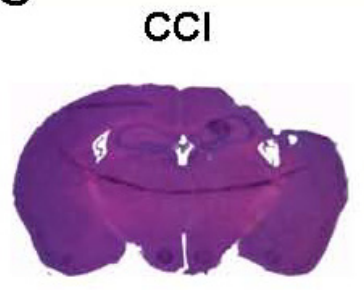

$\mathrm{CCl}+\mathrm{PMN}$ depl

1 week
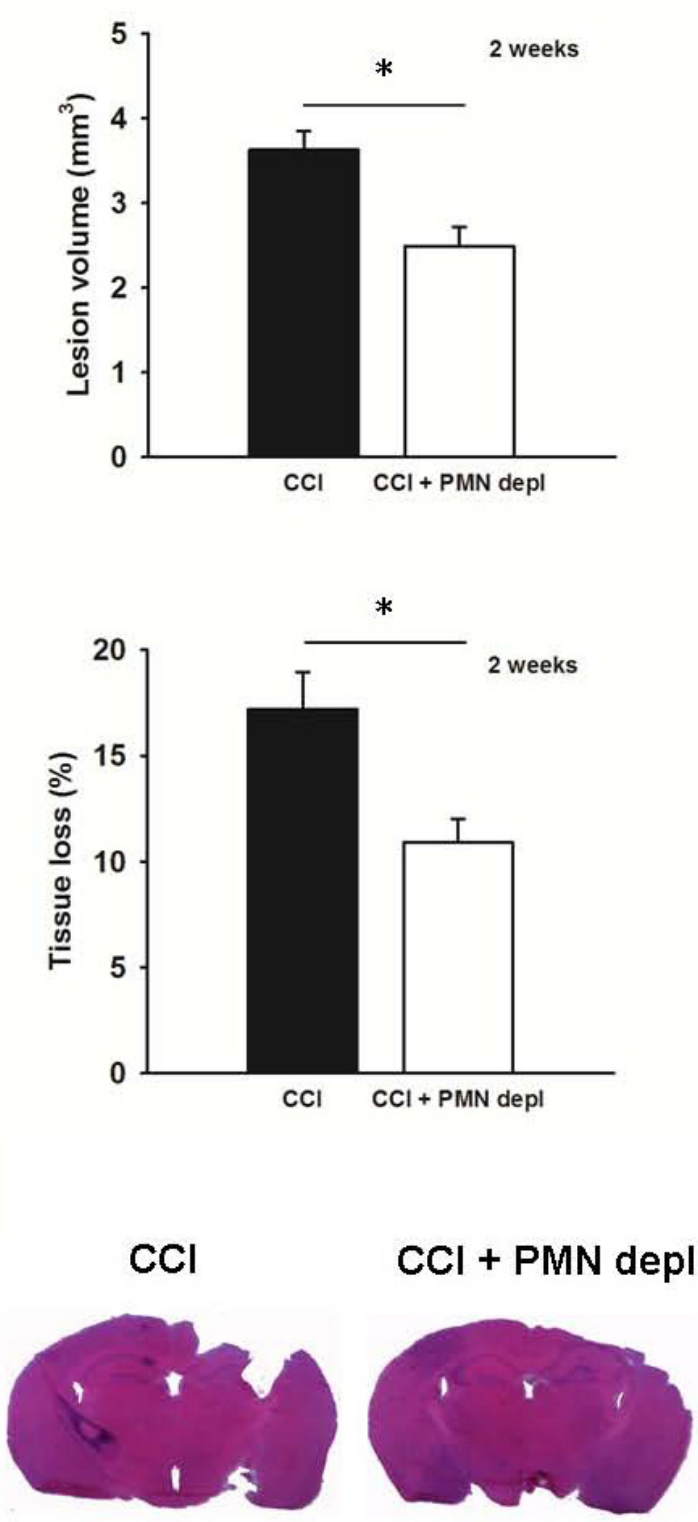

2 weeks

Figure 6 Microglial/macrophage activation is reduced in neutropenic mice. A) Microphotographs of Mac-2 positive cells (green) 7 days after CCI in the cortex and hippocampus. DAPI was used for nuclear staining (blue). Scalebar is $100 \mu \mathrm{m}$. B) Quantification of Mac-2 positive cells in cortex and hippocampus following $\mathrm{CCl}$ (black bars, $\mathrm{n}=5$ ) or $\mathrm{CCl}$ and neutrophil depletion (black bars, $\mathrm{n}=5$ ). * indicates significant difference at $p<0.05$. Values are mean \pm SEM.

attenuated edema formation and reduced tissue loss following experimental TBI $[24,37,38]$. However, the role for PMN has not been elucidated. It has previously been shown that blocking ICAM-1 results in improved neurological scores following brain injury, possibly due to reduced PMN recruitment [39]. In addition, decreased neutrophil recruitment as a result of a deficiency in the chemokine receptor CXCR2 correlated with reduced tissue damage following closed head injury in mice [40]. Further, an attenuation of the acute inflammatory response and edema formation was associated with decreased neuronal damage and behavioral deficits 28 
days after TBI [41]. Moreover, when comparing two different models of TBI (weight drop and CCI), it was shown that the weight drop model gave an increased PMN accumulation, which was associated with a larger lesion volume in those animals [27], providing additional support for the role of PMN in tissue loss.

PMN may aggravate cerebral injury by several mechanisms; especially their ability to secrete MMPs, ROS and cytokines have been implicated in this respect [34]. Inhibiting any of these factors were shown to be neuroprotective in in vivo models of TBI [33,42-44], making the assumption that PMN activation and infiltration is involved in the secondary injury after TBI highly plausible. ROS scavenger treatment lowered ICAM-1 expression and reduced neutrophil recruitment to the rat brain following TBI resulting in attenuated morphological brain damage [6]. In addition, inhibiting the recruitment of PMN to the brain following ischemia-reperfusion injury prevents the increase in MMP-9 [45]. Data like these may explain why treatments resulting in decreased PMN recruitment could lead to attenuated infarct size following ischemia-reperfusion injury $[46,47]$. Our results further strengthen the role for PMN in the tissue damage following TBI.

\section{Conclusion}

In this study we show that neutrophils have a role in edema formation following TBI, possibly most influential on the cytotoxic edema. Furthermore, early neutrophil depletion is effective in reducing the tissue loss that arises secondary to the injury. This association between PMN-induced brain edema and neuronal damage is a novel link in the disease progress following TBI and interference with neutrophil recruitment may be a complementary treatment in the management of TBI.

\section{List of abbreviations}

BBB: blood brain barrier; CCl: controlled cortical impact; DW: dry weight; EB: Evan's blue; ICAM-1: intercellular adhesion molecule-1; ICH: intracerebral hemorrhage; MMPs: matrix metalloproteases; PMN: polymorphonuclear leukocytes; PMN depl: neutrophil depletion; ROS: reactive oxygen species; TBI: traumatic brain injury; WW: wet weight.

\section{Acknowledgements}

This work was funded by grants from the Swedish Research Council (EK, LL, $\mathrm{LH})$, the Swedish Heart-Lung Foundation (EK, LL), the Lars Hierta Memorial Fund (EK, LL), the Swedish Brain Foundation ( $(\mathrm{LH}, \mathrm{FC})$, the Selander Foundation $(\mathrm{LH})$, the Åhlén Foundation $(\mathrm{LH})$ and Uppsala University Hospital $(\mathrm{LH})$

\section{Author details}

'Department of Physiology and Pharmacology, Karolinska Institutet, Stockholm, Sweden. ${ }^{2}$ Department of Neuroscience, Neurosurgery, Uppsala University, Uppsala, Sweden.

\section{Authors' contributions}

EK and FC performed experiments, analyzed data, and contributed to writing of the manuscript. AE, LH and LL participated in the design and coordination of the study as well as helped to draft the manuscript. All authors read and approved the final manuscript.

\section{Competing interests}

The authors declare that they have no competing interests.

Received: 23 September 2011 Accepted: 23 January 2012

Published: 23 January 2012

\section{References}

1. Unterberg AW, Stover J, Kress B, Kiening KL: Edema and brain trauma. Neuroscience 2004, 129:1021-1029.

2. Schmidt OI, Heyde CE, Ertel W, Stahel PF: Closed head injury-an inflammatory disease? Brain Res Brain Res Rev 2005, 48:388-399.

3. Holmin S, Soderlund J, Biberfeld P, Mathiesen T: Intracerebral inflammation after human brain contusion. Neurosurgery 1998, 42:291-298, discussion 298-299.

4. Whalen MJ, Carlos TM, Kochanek PM, Clark RS, Heineman S, Schiding JK, Franicola D, Memarzadeh F, Lo W, Marion DW, Dekosky ST: Neutrophils do not mediate blood-brain barrier permeability early after controlled cortical impact in rats. J Neurotrauma 1999, 16:583-594.

5. Soares HD, Hicks RR, Smith D, Mclntosh TK: Inflammatory leukocytic recruitment and diffuse neuronal degeneration are separate pathological processes resulting from traumatic brain injury. J Neurosci 1995, 15:8223-8233.

6. Clausen F, Lorant $T$, Lewen A, Hillered L: T lymphocyte trafficking: a novel target for neuroprotection in traumatic brain injury. J Neurotrauma 2007, 24:1295-1307.

7. Clark RS, Carlos TM, Schiding JK, Bree M, Fireman LA, DeKosky ST, Kochanek PM: Antibodies against Mac-1 attenuate neutrophil accumulation after traumatic brain injury in rats. J Neurotrauma 1996, 13:333-341.

8. Carlos TM, Clark RS, Franicola-Higgins D, Schiding JK, Kochanek PM: Expression of endothelial adhesion molecules and recruitment of neutrophils after traumatic brain injury in rats. J Leukoc Biol 1997, 61:279-285.

9. Wedmore CV, Williams TJ: Control of vascular permeability by polymorphonuclear leukocytes in inflammation. Nature 1981, 289:646-650.

10. Lindbom L: Regulation of vascular permeability by neutrophils in acute inflammation. Chem Immunol Allergy 2003, 83:146-166.

11. Arfors KE, Lundberg C, Lindbom L, Lundberg K, Beatty PG, Harlan JM: A monoclonal antibody to the membrane glycoprotein complex CD18 inhibits polymorphonuclear leukocyte accumulation and plasma leakage in vivo. Blood 1987, 69:338-340.

12. Schoettle RJ, Kochanek PM, Magargee MJ, Uhl MW, Nemoto EM: Early polymorphonuclear leukocyte accumulation correlates with the development of posttraumatic cerebral edema in rats. J Neurotrauma 1990, 7:207-217

13. Hartl R, Medary MB, Ruge M, Arfors KE, Ghajar J: Early white blood cell dynamics after traumatic brain injury: effects on the cerebral microcirculation. J Cereb Blood Flow Metab 1997, 17:1210-1220.

14. Uhl MW, Biagas KV, Grundl PD, Barmada MA, Schiding JK, Nemoto EM, Kochanek PM: Effects of neutropenia on edema, histology, and cerebral blood flow after traumatic brain injury in rats. J Neurotrauma 1994, 11:303-315.

15. Jin R, Yang G, Li G: Inflammatory mechanisms in ischemic stroke: role of inflammatory cells. J Leukoc Biol 2010, 87:779-789.

16. Ikegame Y, Yamashita K, Hayashi S, Yoshimura S, Nakashima S, Iwama T: Neutrophil elastase inhibitor prevents ischemic brain damage via reduction of vasogenic edema. Hypertens Res 2010, 33:703-707.

17. Morancho A, Rosell A, Garcia-Bonilla L, Montaner J: Metalloproteinase and stroke infarct size: role for anti-inflammatory treatment? Ann N Y Acad Sci 2010, 1207:123-133

18. Moxon-Emre I, Schlichter LC: Neutrophil depletion reduces blood-brain barrier breakdown, axon injury, and inflammation after intracerebral hemorrhage. J Neuropathol Exp Neurol 2011, 70:218-235.

19. Zhuang J, Shackford SR, Schmoker JD, Anderson ML: The association of leukocytes with secondary brain injury. J Trauma 1993, 35:415-422.

20. Emerich DF, Dean RL, Bartus RT: The role of leukocytes following cerebral ischemia: pathogenic variable or bystander reaction to emerging infarct? Exp Neurol 2002, 173:168-181. 
21. Dixon CE, Clifton GL, Lighthall JW, Yaghmai AA, Hayes RL: A controlled cortical impact model of traumatic brain injury in the rat. J Neurosci Methods 1991, 39:253-262.

22. Clausen F, Hanell A, Bjork M, Hillered L, Mir AK, Gram H, Marklund N: Neutralization of interleukin-1beta modifies the inflammatory response and improves histological and cognitive outcome following traumatic brain injury in mice. Eur J Neurosci 2009, 30:385-396.

23. Soehnlein O, Oehmcke S, Ma X, Rothfuchs AG, Frithiof R, van Roijen N, Morgelin $M$, Herwald $H$, Lindbom L: Neutrophil degranulation mediates severe lung damage triggered by streptococcal M1 protein. Eur Respir $J$ 2008.

24. Clausen F, Hanell A, Israelsson C, Hedin J, Ebendal T, Mir AK, Gram H, Marklund N: Neutralization of interleukin-1beta reduces cerebral edema and tissue loss and improves late cognitive outcome following traumatic brain injury in mice. Eur J Neurosci 2011.

25. Zhang C, Raghupathi R, Saatman KE, Smith DH, Stutzmann JM, Wahl F, McIntosh TK: Riluzole attenuates cortical lesion size, but not hippocampal neuronal loss, following traumatic brain injury in the rat. J Neurosci Res 1998, 52:342-349.

26. Kochanek PM, Marion DW, Zhang W, Schiding JK, White M, Palmer AM, Clark RS, O'Malley ME, Styren SD, Ho C, et al: Severe controlled cortical impact in rats: assessment of cerebral edema, blood flow, and contusion volume. J Neurotrauma 1995, 12:1015-1025.

27. Clark RS, Schiding JK, Kaczorowski SL, Marion DW, Kochanek PM: Neutrophil accumulation after traumatic brain injury in rats: comparison of weight drop and controlled cortical impact models. J Neurotrauma 1994, 11:499-506.

28. Hellal F, Bonnefont-Rousselot D, Croci N, Palmier B, Plotkine M, MarchandVerrecchia C: Pattern of cerebral edema and hemorrhage in a mice model of diffuse brain injury. Neurosci Lett 2004, 357:21-24.

29. Whalen MJ, Carlos TM, Kochanek PM, Heineman S: Blood-brain barrier permeability, neutrophil accumulation and vascular adhesion molecule expression after controlled cortical impact in rats: a preliminary study. Acta Neurochir Suppl 1998, 71:212-214.

30. Engelhardt B, Sorokin L: The blood-brain and the blood-cerebrospinal fluid barriers: function and dysfunction. Semin Immunopathol 2009, 31:497-511.

31. Biber N, Toklu HZ, Solakoglu S, Gultomruk M, Hakan T, Berkman Z, Dulger FG: Cysteinyl-leukotriene receptor antagonist montelukast decreases blood-brain barrier permeability but does not prevent oedema formation in traumatic brain injury. Brain Inj 2009, 23:577-584.

32. Shapira Y, Setton D, Artru AA, Shohami E: Blood-brain barrier permeability, cerebral edema, and neurologic function after closed head injury in rats. Anesth Analg 1993, 77:141-148.

33. Lewen A, Matz P, Chan PH: Free radical pathways in CNS injury. $J$ Neurotrauma 2000, 17:871-890.

34. Nguyen HX, O'Barr TJ, Anderson AJ: Polymorphonuclear leukocytes promote neurotoxicity through release of matrix metalloproteinases, reactive oxygen species, and TNF-alpha. J Neurochem 2007, 102:900-912.

35. Rivest S: Regulation of innate immune responses in the brain. Nat Rev Immunol 2009, 9:429-439.

36. Soehnlein O, Zernecke A, Eriksson EE, Rothfuchs AG, Pham CT, Herwald H, Bidzhekov K, Rottenberg ME, Weber C, Lindbom L: Neutrophil secretion products pave the way for inflammatory monocytes. Blood 2008, 112:1461-1471.

37. Khan M, Im YB, Shunmugavel A, Gilg AG, Dhindsa RK, Singh AK, Singh I: Administration of S-nitrosoglutathione after traumatic brain injury protects the neurovascular unit and reduces secondary injury in a rat model of controlled cortical impact. J Neuroinflammation 2009, 6:32.

38. Zhu ZF, Wang QG, Han BJ, William CP: Neuroprotective effect and cognitive outcome of chronic lithium on traumatic brain injury in mice. Brain Res Bull 2010, 83:272-277.

39. Knoblach SM, Faden Al: Administration of either anti-intercellular adhesion molecule- 1 or a nonspecific control antibody improves recovery after traumatic brain injury in the rat. J Neurotrauma 2002, 19:1039-1050

40. Semple BD, Bye N, Ziebell JM, Morganti-Kossmann MC: Deficiency of the chemokine receptor CXCR2 attenuates neutrophil infiltration and cortical damage following closed head injury. Neurobiol Dis 2010, 40:394-403.

41. Lloyd E, Somera-Molina K, Van Eldik L, Watterson DM, Wainwright MS: Suppression of acute proinflammatory cytokine and chemokine upregulation by post-injury administration of a novel small molecule improves long-term neurologic outcome in a mouse model of traumatic brain injury. J Neuroinflammation 2008, 5:28

42. Wang $X$, Jung J, Asahi M, Chwang W, Russo L, Moskowitz MA, Dixon CE, Fini ME, Lo EH: Effects of matrix metalloproteinase-9 gene knock-out on morphological and motor outcomes after traumatic brain injury. $J$ Neurosci 2000, 20:7037-7042.

43. Shohami E, Gallily R, Mechoulam R, Bass R, Ben-Hur T: Cytokine production in the brain following closed head injury: dexanabinol (HU-211) is a novel TNF-alpha inhibitor and an effective neuroprotectant. $J$ Neuroimmunol 1997, 72:169-177.

44. Marklund N, Lewander T, Clausen F, Hillered L: Effects of the nitrone radical scavengers $\mathrm{PBN}$ and $\mathrm{S}-\mathrm{PBN}$ on in vivo trapping of reactive oxygen species after traumatic brain injury in rats. J Cereb Blood Flow Metab 2001, 21:1259-1267.

45. Justicia C, Panes J, Sole S, Cervera A, Deulofeu R, Chamorro A, Planas AM: Neutrophil infiltration increases matrix metalloproteinase- 9 in the ischemic brain after occlusion/reperfusion of the middle cerebral artery in rats. J Cereb Blood Flow Metab 2003, 23:1430-1440.

46. Matsuo $Y$, Onodera $H$, Shiga $Y$, Nakamura M, Ninomiya M, Kihara T, Kogure K: Correlation between myeloperoxidase-quantified neutrophil accumulation and ischemic brain injury in the rat. Effects of neutrophil depletion. Stroke 1994, 25:1469-1475.

47. Matsuo Y, Onodera H, Shiga Y, Shozuhara H, Ninomiya M, Kihara T, Tamatani T, Miyasaka M, Kogure K: Role of cell adhesion molecules in brain injury after transient middle cerebral artery occlusion in the rat. Brain Res 1994, 656:344-352.

\section{doi:10.1186/1742-2094-9-17}

Cite this article as: Kenne et al:: Neutrophil depletion reduces edema formation and tissue loss following traumatic brain injury in mice. Journal of Neuroinflammation 2012 9:17.

\section{Submit your next manuscript to BioMed Central and take full advantage of:}

- Convenient online submission

- Thorough peer review

- No space constraints or color figure charges

- Immediate publication on acceptance

- Inclusion in PubMed, CAS, Scopus and Google Scholar

- Research which is freely available for redistribution
C BioMed Central 